\begin{tabular}{|c|c|c|}
\hline & $\begin{array}{l}\text { ANNALES INSTITUTI SLAVICI } \\
\text { UNIVERSITATIS DEBRECENIENSIS }\end{array}$ & \\
\hline SLAVICA XLVIII & 2019 & DEBRECEN \\
\hline
\end{tabular}

Дмитрий РЕУт

\title{
МЕТОДОЛОГИЯ ТРАНСДИСЦИПЛИНАРНОСТИ: ПРОКРЕАЦИОННЫЙ КАПИТАЛ КАК БАЗОВЫЙ ФАКТОР ЖИЗНЕСПОСОБНОСТИ ЦИВИЛИЗАЦИОННО- кУльтУРнОЙ Единицы
}

\author{
Trans-Disciplinary Methodology: Procreation Capital as a Basic Factor \\ in the Viability of a Civilizational-Cultural Unit
}

\begin{abstract}
The main problem raised in the paper is in line with a new trend of research, conceptual programs and practical activity that can be termed "hygiene of culture". The study is transcritical in its character and proposes to consider the category of capital generated by the economy in relation to the reproduction of the population in its structural units of civilization and as a cultural community. Trans-discipline methodology is currently being developed, which makes the work is up-to-date. It develops basic aspects of the procreation capital category, which claims to be a generalization of the human capital category. The problem is the restoration of European culture, which has been eroded by the distortion of the ideas of market economy. The reason why it is particularly urgent to find a solution to the problem is the threat posed by the demographic situation of the developed countries of European culture and the adjacent countries of the Slavic-Orthodox cultural cluster by the actual organization of housing.
\end{abstract}

Keywords: hygiene of culture, reproduction, structural unit, cultural identity, population, systems drawn on systems, metaphor, global system, European culture, human capital, economy, institute, demography, subject of history

\section{Введение}

Дисциплина «гигиена культуры» плодотворно развивается уже более десяти лет благодаря инициативе и непрерывной организационной поддержке Ассоциации «за Венгерско-Российское сотрудничество имени Льва Николаевича Толстого» под руководством д-ра О. Сюч [SZUCS 2018a, SZUCS 2018b].

Объектом исследования является цивилизационно-культурная единица в составе совокупности цивилизационно-культурных единиц.

Предмет исследования - способ поддержания жизнеспособности цивилизационно-культурной единицы (способ существования цивилизационно-культурной единицы и совокупности названных единиц).

Гипотеза: способ существования цивилизационно-культурной единицы и совокупности названных единиц состоит в непрерывном обращении прокреационного капитала, обеспечиваемом наличием прокреационной ренты либо требующем специальных организационно-экономических мер для своего осуществления. 
Данная статья, с одной стороны, продолжает направление исследований новой социально-экономической категории «Прокреационный капитал» [РЕУТ 2009], а, с другой стороны, посвящена развитию используемой в антропологии и смежных дисциплинах категории «Культурная единица» [РЕУТ 2019]. Очевидно, предлагаемое вниманию читателя исследование трансдисциплинарно. Методология трансдисциплинарных исследований находится в стадии становления. Поэтому мы не всегда можем даже обойтись накопленным в научно-философском дискурсе терминологическим запасом и будем вынуждены обращаться к метафорам или/и предлагать новые термины.

Справедливости ради отметим, что единства представлений о «капитале» мы не находим даже внутри породившей эту категорию дисциплины - экономики. Потенциал категории «капитал» даже «не оконтурен». Между прочим, термин «оконтурить», выбранный нами для характеристики ситуации, принадлежит уже естественно-научной дисциплине геологии.

\section{Методы исследования}

Продолжим терминологическое пояснение заголовка статьи. Под прокреацией мы понимаем воспроизводство жизни, воспроизводство коренного населения культурных единиц как пространственно-укорененных образований в составе глобальной системы рассматриваемой цивилизационно-культурной общности. Прокреация включает также условия воспроизводства жизни предшествующие и способствующие воспроизводству, а также факторы этого воспроизводства и его процесс, включающий специфические механизмы и характеризуемый совокупностью текущих результатов.

Итак, объектом исследования нами выбрана цивилизационно-культурная единица. Культурная, а точнее - цивилизационно-культурная общность как произвольная целостность может быть представлена в виде совокупности цивилизационно-культурных единиц - встроенных одна в другую или рядоположенных и практикующих социальную, во многих отношениях - культурную - политику. Уточнение, связанное с категорией цивилизации требует ссылки, например, на программную работу О. Шпенглера [SPENGLER 1927]. Мы не можем в рамках небольшой статьи вдаваться в обсуждение степени зрелости той или иной культуры на пути ее трансформации в цивилизацию или степени исчерпанности потенциала ее развития. Поэтому здесь мы не будем проводить границу между культурной, социокультурной и цивилизационно-культурной общностью.

Ведь наше исследование осуществляется в онтологии многослойного исторического процесса. В культуре существуют виды активности разной направленности и степени обобщенности.

Рассматривая культуру в континуальном залоге, исследователи обнаруживают тончайшие взаимные влияния далеко отстоящих культурных трендов. Однако прочно укоренное в научном дискурсе понятие культурного явления говорит о широком использовании также и дискретного залога. Культурные 
феномены выделяются культурологами относительно культурного фона средствами своей дисциплины или смежных дисциплин. Здесь кстати приходится новый научный предмет - лимология - озабоченный обоснованием демаркации любого рода границ в пространстве и времени. Здесь мы вынуждены ограничиться лишь упоминанием этого многообещающего термина.

Примером может служить современность - грань между прошлым и будущим. Она представляет собой «сокрушительную силу» [GIDDENS 1990: 4]. Ведь в ней разворачиваются разнонаправленные процессы, приводящие в движение огромные массы людей и наличные ресурсы планеты. Под современностью Гидденс понимает «способы социальной жизни или организации, возникшие в Европе начиная с XVII столетия и впоследствии оказавшие влияние на весь остальной мир» [GIDDENS 1990: 12]. Социальность у Гидденса укоренена в определенном культурном ареале. Это вызывает ассоциации с термином «культурная единица», также территориально обусловленном.

Сегодня термин «культурная единица» живет, прежде всего, в таких автономных и самодостаточных (по разным причинам) дисциплинах, как антропология и менеджмент культурных учреждений.

В антропологии понятие «культурная единица» используется для того, чтобы описать культуру как целое или диагностировать ее состояние. Ее основой является произвольная социальная целостность, на которой сформировалась отдельная культура, характеризуемая устойчивой совокупностью черт. Исторически сформированы механизмы их воспроизводства от поколения к поколению в устойчивых конфигурациях.

Предпримем шаги к раскрытию исторически сложившейся структуры цивилизационно-культурной общности, к которой мы принадлежим, и способа ее существования, например, увидев в ней крупномасштабную систему - совокупность нескольких ярусов «нарисованных друг на друге» подсистем, различающихся масштабом, скоростью протекающих процессов и средней продолжительностью существования. Концепция «нарисованных друг на друге» подсистем принадлежит российскому психологу В. Лефевру [LEFEBVRE 1982]. Конкретизируем эту квалификацию. На основании анализа эмпирического материала мы в данном исследовании предлагаем различать - в порядке нарастания масштаба протекающих процессов - пять классов подсистем, соответствующих следующим пространствам: 1) хозяйственно-экономической деятельности, 2) социальной деятельности, 3) прокреационно-демографическому пространству (или пространству истории), 4) пространству культурной интеграции, 5) планетарному пространству. В зависимости от целей исследователя количество обсуждаемых классов может варьироваться. Критерием отнесения системы деятельности и осуществляющего ее субъекта к тому или другому классу служат последовательные ответы на ряд вопросов: входит ли в цели рассматриваемого субъекта достижение и/или поддержание: 1) хозяйственноэкономической состоятельности, 2) также (в дополнение к предыдущему) и социальной состоятельности, 3) также и состоятельности прокреационной, 
4) также и состоятельности культурной интеграции, обеспечивающей культурную целостность, 5) также и состоятельности экологической?

Под состоятельностью мы понимаем способность обеспечивать в течение времени, неограничиваемого очевидными современникам причинами, протекание базовых процессов подсистемы и поддерживать существование обеспечивающих протекание этих процессов структур, соответствующих рассматриваемому аспекту совокупной крупномасштабной системы.

Следующим шагом исследования может стать рассмотрение перекрестных воздействий между заявляемыми исследователем классами подсистем.

В пространственном аспекте мы отталкиваемся от рассмотрения глобальной системы, выделяя в ней подсистемы различных масштабов, «нарисованные друг на друге». Естественно предпринять аналогичный «ход» по отношению ко времени. Будем различать два временны́х масштаба: «длинное» или эволюционное время, в котором разворачивается естественный обор, и «короткое» время, в пределах которого человек осуществляет согласно своему ограниченному разумению искусственный отбор «лучших» практик. Актуально существуя в «коротком» времени, человек понимает границы его условного горизонта в техническом смысле. Иными словами, он заботится о собственной состоятельности лишь в пределах горизонта тактического или, в лучшем случае, стратегического планирования развития коллективного субъекта, к которому человек себя причисляет. Мы полагаем, что, если говорить об управлении системой масштаба региона или страны, то стратегический горизонт управленца не может быть меньше цикла основного процесса, протекающего в прокреационно-демографическом (третьем) слое глобальной системы, т.е. цикла воспроизводства поколений - не менее 25 лет. Ведь прокреационно-демографические процессы являются «подстилающими» для культурно-интеграционных, оформляющих культурные единицы типа регионов и сран.

Крупномасштабная система в нашей концепции представляет собой совокупность двух и более «нарисованных друг на друге» подсистем, принадлежащих различным классам описанного выше классификатора. Для своего устойчивого функционирования и развития она требует специфического управления, отличного от управления систем, не являющихся крупномасштабными, поскольку это управление должно строиться с учетом более, чем одной теоретической действительности (например, экономической или социальной).

Глобальная система, безусловно являющаяся крупномасштабной, охватывает все пять названных классов, «слоев». Цивилизационно-культурная общность - до четырех нижних, поскольку ответственность за сохранность экологического окружения ее субъекту (т.е. человечеству) взять на себя пока не удается.

Структура культурной единицы, базируясь на хозяйственно-экономическом субстрате, «прорастает» в один или несколько слоев глобальной системы: социальный, прокреационно-демографический, культурно-интеграционный. Мы бытийствуем в глобальной системе, представляющей собой совокупность взаимодействующих разноуровневых культурных единиц. 
Культурные единицы, достигшие культурно-интеграционного слоя и укоренившиеся в нем, способны оказывать активное влияние на культурно-цивилизационную общность в целом, т.е. оказываются субъектами культурной политики. Прочие культурные единицы оказываются для них объектами (ресурсом). Актуален вопрос построения матрицы транс-дисциплинарных (межуровневых) влияний, о выделении в этой матрице желаемых и «запретных» областей - с точки зрения устойчивости развития глобальной системы. В прошлом считалось, что «у человечества как такового» нет никакой цели, никакой идеи, никакого плана, как нет цели у вида бабочек или орхидей» [SPENGLER 1927: 137]. Сегодня становится очевидным, что такая ситуация ведет к скорому исчерпанию ресурсов планеты с печальным финалом.

В просторечии совокупность четырех перечисленных слоев, складывающаяся из культурно-цивилизационных единиц, обозначается как конкретная (например, европейская) культура в целом. Анализ позволяет различить на этом фоне культурные единицы, актуализированные на данном этапе развития общества. Сказанное относится не только к локальным цивилизациям в смысле Тойнби, но и более мелким единицам исследования, включая субкультуры. Культурные единицы могут взаимодействовать на каждом из вышеназванных уровней в любом сочетании. Такие взаимоотношения могут классифицироваться и исследоваться с помощью вышеупомянутых матриц трансдисциплинарных влияний.

Важным инструментом трансдисциплинарных исследований является работа в категориальных парах, в частности естественное-искусственное.

По нашим представлениям, цивилизационно-культурный единицы существуют, воспроизводятся и развиваются прежде всего в составе исторически складывающихся популяций [DARWIN 1859]. Последние, если применять данный термин к цивилизационно-культурным единицам, являются естественноискусственными организованностями. Мы будем понимать их как «матрешечно» организованные сущности, наращивающие число слоев по мере развития за счет привлечения новых членов, пока этот процесс не будет уравновешен центробежными тенденциями, порождаемыми ситуативными и стратегическими противоречиями. Для пояснения способа ее существования обратимся к рассмотрению экономического слоя крупномасштабной системы.

Конечно, современная экономика не покрывает всей совокупности человеческого опыта. Институт экономики (в сложившемся к настоящему моменту понимании термина) не является самодостаточным фундаментом существования социума. И дело даже не в мировых финансово-экономических кризисах. О функциональной неполноте современного экономического мышления свидетельствует общеизвестная демографическая статистика. Ни одна экономически развитая страна Европейской культуры (в широком смысле, включая США) не в состоянии обеспечить даже простого воспроизводства своего коренного населения, несмотря на все принимаемые меры. Поскольку указанный тренд непреодолим наличными финансово-экономическими, научными, социальными и т.д. средствами, то убыль коренного населения или человеческого 
капитала «брутто» не может не привести к дефициту человеческого капитала «нетто» или - в современной терминологии - просто человеческого капитала в тех показателях, в которых эта категория сегодня трактуется в экономической теории и практике.

Приходит время возвращения экономической науки и практики к своему исходному широкому значению - значению искусства ведения домашнего хозяйства (oikonomike, греч.), или искусства хозяйства страны, конструктивно сводящего в едином концептуальном пространстве такие разнородные категории, как, например, деторождение и капитал.

Нетрудно видеть разрывы между текущей численностью населения европейских стран и современным кругом понятий, обслуживающих капиталистическое производство.

Со времен А. Смита при решении любых экономических задач количество рабочей силы предполагалось избыточным. Позиция классика понятна - этот выдающийся шотландский экономист был провозвестником буржуазно-промышленной революции, в ходе которой ручной труд в массовом порядке замещался более производительным машинным. С тех пор производственные технологии все более оискусствляются.

Параллельно техническому прогрессу в истории Европы набирал силу прогресс социальный. Его движущей силой на протяжении веков оставался дух Великой французской энциклопедии с лозунгами свободы, равенства и братства, которые дали жизнь современной концепции прав человека. Однако проекция этих идей на европейскую повседневность окрасилась оттенками индивидуализма и эгоизма, сначала на уровне конкурентного капиталистического предприятия, а затем и на уровне среднеевропейской семьи. Характерный для капиталистической социальности императив личного успеха любой ценой потребовал массовых «человеческих жертв»: множество семей развитых стран Европы ради сохранения достигнутого уровня потребления откладывало и продолжает откладывать рождение детей на неопределенное время. Полностью оставаясь в рамках прав человека, они вполне добровольно отказываются от исполнения прокреационной функции.

Формальным гарантом процветания европейской страны является социальное государство. В понятие процветания входит и воспроизводство населения, поскольку вымирающую страну трудно назвать процветающей. Однако государственные чиновники не строят прокреационной стратегии и не обеспечивают ее реализацию. Поэтому рычаги воздействия на прокреационный процесс у них отсутствуют. Простое воспроизводство требует коэффициента рождаемости 2,14 - 2.16. Даже такая богатая страна, как США, тратящая $12 \%$ ВВП на медицину и разворачивающая мощные социальные программы, не достигает гомеостатического уровня.Убыль коренного населения восполняется иммигрантами, принадлежащими соседним народам традиционных культур.

Итак, можно зафиксировать наличие угрожающей демографической ситуации стран европейской (в широком смысле) культуры и примыкающего 
к нему по фактической организации домоустроения ряду стран славянско-православного культурного кластера [РЕУт 2008]. Ее преодоление предлагается начать с использования трансдисциплинарного подхода; расширения трактовки человеческого капитала до пределов капитала базового, т.е. обеспечивающего обладающему им коллективному субъекту статуса субъекта истории. Этот статус означает, что его владелец способен длить свое существование на исторической арене в течение срока, неограничиваемого очевидными современникам причинами. Этот статус эквивалентен простому либо расширенному (в ближайшей временной перспективе) воспроизводству коренного населения.

Интересующую нас характеристику этого населения (обеспечивающую в перспективе и всю получаемую в социуме прибыль) можно обозначить как человеческий капитал «брутто» или прокреационный капитал.

В одном из многочисленных значений капитал есть стоимость (понимаемая нами в широком смысле), которая в результате предпринимательских или иных видов деятельности приносит прибавочную стоимость.

Стоимость (понимаемая нами также в широком смысле) - экономическая категория общественного производства, представляющая собой овеществленный в товаре общественный труд.

Тогда прокреационный капитал есть прокреационно-демографическая категория (этим термином дается отсылка к слою в составе крупномасштабной системы), представляющая собой овеществленный в наличной популяции общественный труд, направленный на воспроизводство этой популяции. Воспроизводство осуществляется деторождением и социализацией подрастающих членов социума, как минимум, замещающими выбывающих в силу возрастных причин членов.

Инвестиции в общеизвестные формы человеческого капитала приносят инвестору прибыль в сроки, сопоставимые с другими современными бизнес-операциями. Результатов же инвестиций в прокреацию лицо, принимающее решение о таких инвестициях, не дождется в силу краткости срока своей профессиональной деятельности. Прокреационный капитал имеет сверхдлинный (25 лет и более) срок обращения. Отсюда следует абсолютная безответственность бюрократии в вопросах прокреации. Современное капиталистическое государство не имеет механизмов защиты своих долговременных интересов.

Наиболее полно основания построения прокреационной политики государства выразил французский экономист, врач по образованию Франсуа Кенэ (1694 - 1774), претендовавший на пост министра финансов при дворе Людовика XV. Исторически Кенэ предшествовал А. Смиту. Его работы были оценены К. Марксом, который, впрочем, отметил ошибочность исходных посылок исследования, состоявших в их построении на основе аграрного, а не промышленного производства. Но важно то, что Кенэ точно указал на государство (тогда это было королевство) как насубъекта хозяйствования, чье основное богатство составляет население. Ведь ежегодно производимый совокупный сельскохозяйственный продукт пропорционален численности землепашцев. Последующие экономисты, включая А. Смита, Т. Мальтуса, К. Маркса, Д. Кейнса 
и др. - развивали свою науку уже с совершенно иной точки зрения (внедренной в умы экономистов А. Смитом) - с позиции индивидуального предпринимателя или хозяина мануфактуры, действующего в условиях избытка рабочей силы и максимизирующего производство товара или свою денежную прибыль. Таким образом, приоритеты экономической науки претерпели кардинальное изменение вследствие не афишируемой смены точки сборки.

Условным владельцем прокреационного капитала может оказаться только достаточно крупный коллективный субъект - масштаба региона, страны, группы стран. Условность владения объясняется тем, что в условиях демократического государства с присущим ему институтом прав человека этот коллективный субъект не является абсолютным собственником результата. Крепостное право отменено, общественный договор содержит множество неопределенностей.

Отечественная рабочая сила покупается государством, зарубежными и отечественными капиталистами на рынке труда, часто - по демпинговым ценам.

Но способность трудиться является лишь одним из аспектов учетной единицы человеческого капитала «брутто», приобретаемого человеком по факту рождения, созревающего и увядающего по естественным законам в течение жизненного цикла и окончательно утрачиваемого им в момент смерти. В течение жизненного цикла индивид в достаточной степени волен предпринимать акты воспроизводства человеческого капитала «брутто», в основном, в пользу будущих поколений (в отличие от ситуации в странах традиционных культур, где потомство обеспечивает старость индивида), а также продавать его на внутреннем рынке труда (точнее, продавать его «нетто»-составляющую), вывозить его за рубеж посредством институтов легальной или нелегальной эмиграции, гастарбайтерства, вступать на путь асоциального экономического поведения (теневой бизнес, преступность), либо предпринимать «внутреннюю эмиграцию», предаваясь пьянству и наркотикам.

Государству в долговременной перспективе выгодно вступать с индивидом в партнерские отношения, разрабатывая и последовательно осуществляя внутреннюю политику расширенного воспроизводства человеческого капитала «брутто» [ORLOV 2013, ORLOV 2018, TSVIRKUN-VARNAVSKY 2017, TSVIRKUNVASILIEV 2007] Пути такого культурно обоснованного и психологически приемлемого сотрудничества предстоит системно разрабатывать в составе инновационного института прокреации, поскольку разрозненные попытки решить демографическую проблему мероприятиями типа учреждения материнского капитала оказываются недостаточными.

Перекрывая в собственной стране возможности воспроизводства человеческого капитала «брутто», современное экономически развитое государство предопределяет исчерпание человеческого капитала «нетто» и вынуждено импортировать его, расплачиваясь за это нарастающей угрозой тиражирования косовской трагедии. 


\section{Результаты}

В контексте широко понимаемой экономики предложена категория прокреационного капитала, являющаяся обобщением категории человеческого капитала в составе современного экономического инструментария. В связи с медленным темпом обращения прокреационного капитала его владельцем может быть только субъект истории или претендент на этот статус - достаточно крупный коллективный субъект масштаба региона, страны, группы стран. Предложены пути работы с прокреационным капиталом, парирующие угрожающую демографическую ситуацию стран европейской культуры и примыкающего к нему по фактической организации домоустроения ряду стран славянско-православного культурного кластера.

\section{Обсуждение}

Какова же динамика «сплавления» хозяйственно-экономического рынка с прокреационной ситуацией в реальности? Она отражается движением прокреационного капитала. Производными от его величины оказываются размер контролируемой «владельцем» прокреационного капитала территории, а также численность популяции не только производителей, но и покупателей. Кстати, это заставляет проблематизировать, казалось бы, бесспорную сентенцию: рациональным может быть поведение государства, а не его размеры.

Для обществ традиционных культур семья является устойчивым источником прокреационной ренты. Развитые страны неосознанно прилагают немало усилий к уничтожению этого источника, и существование этих стран зависит от того, насколько эффективно они выстроят цикл обращения своего прокреационного капитала.

Мы попытаемся показать, когда и почему экономика утратила исторические горизонты, и предложить - в целях разрешения кризисной демографической ситуации - начать обратное «маятниковое» движение в развитии экономического концептуального инструментария. Статус субъекта истории может быть обеспечен субъекту деятельности посредством владения прокреационным капиталом. Последний не имеет регулярных механизмов конвертации с капиталом финансовым. Поэтому в исследовании приходится отказаться от марксовой идеологии денег как всеобщего эквивалента и обращаться, наряду с количественными, к структурным методам исследования.

Но какая же ассоциация позволяет называть прокреационный капитал именно капиталом? Это - отношение прокреационного капитала к человеческому капиталу как сущности «брутто» к сущности «нетто». Прокреационный капитал есть человеческий капитал, «упакованный» в «оболочку» населения. Утрата субъектом деятельности статуса субъекта истории вызвана неосознанным уничтожением им источника прокреационной ренты и неэффективностью управления наличным прокреационным капиталом. 
Прокреационный капитал не тождественен численности населения территории, он включает также прокреационную среду, создающую достаточно благоприятные условия для воспроизводства населения. Это обстоятельство всегда лежало вне горизонта как экономических, так и медицинских исследований. Необходимые инвестиции в прокреационный капитал включают финансовую составляющую, далеко не ограничиваясь ею.

Величина прокреационного капитала не имеет выражения в денежном эквиваленте. Поэтому прокреационный капитал не подвержен инфляции. Минимально необходимый размер человеческого капитала «брутто» субъекта истории определяется количеством населения, необходимым для удержания территории. Мы говорим об устойчивости по отношению к «просачиванию» соседей посредством легальной и нелегальной миграции и еепрокреационных последствий, зависящей, в частности, от реально реализуемой иммиграционной политики.

Некоторую долю в человеческий капитал «нетто» могут вносить иммигранты и гастарбайтеры. А вот возможность их включения в человеческий капитал «брутто» обусловлена требованием культурной ассимиляции, которая занимает значительное время, а иногда по факту не происходит на протяжении жизни нескольких поколений. Именно поэтому образующее прокреационный капитал население должно быть оседлым, точнее - задающим культурную идентичность наличествующей государственной формы.

Реализуемые сегодня мероприятия по стимулированию рождаемости, требующие концептуальных проработок, законодательных инициатив, институциональных преобразований, социальной рекламы и денежных вложений, могут через двадцать - пятьдесят лет дать (или не дать):

А) прямой результат в виде коррекции демографического баланса региона, страны. Прокреационный капитал имеет вероятностную природу дохода, выражаемого в натуральных показателях, зависящую не только от соотношения хозяйственно-экономических факторов и природных условий, но также от конфигурации социокультурных институтов и мейнстрима общественной мысли, воплощаемого в структурах повседневности.

Б) побочный результат в виде прироста рабочей силы на рынке труда, также непосредственно не конвертируемый в деньги. В зависимости от конъюнктуры и политической обстановки рабочая сила вольна принимать независимые решения в отношении своего гражданства и рыночного позиционирования.

При реализации третьего пути экономики интересы государства европейской культуры должны базироваться на прокреационном императиве. Успешная прокреационная стратегия и политика государства возможна на основе института, который будет включать не только соответствующую законодательную базу и средства ее реализации, но и социокультурную составляющую. Построение эффективного института прокреации в отдельно взятой стране затруднительно в связи с доминированием агрессивной идеологи потребительского общества и бурным развитием транслирующих ее средств массовых коммуникаций. Возникает задача международной кооперации. Для ее решения должно 
быть достигнуто общее понимание, что безусловной альтернативой успешного разрешения поставленной проблемы является исчезновение европейского мира

Кратко резюмируем свойства прокреационного капитала.

При переходе от исследований физиократов к исследованиям экономистов эпохи мануфактурного производства была пройдена точка бифуркации в развитии экономики, отделившая дисциплину устроения и развития «дома» как единого целого от дисциплины обеспечения эффективности производственной, хозяйственной деятельности отдельного субъекта.

Инструментом возвращения к исходному смыслу экономики может послужить предлагаемая нами категория прокреационного капитала. Прокреационный капитал есть обобщение человеческого капитала, относящееся к нему, как сущность «брутто» к сущности «нетто». Прокреационный капитал не тождествен численности населения территории, он включает также прокреационную среду, создающую благоприятные условия для воспроизводства населения. Прокреационный капитал обладает сверхдлинным сроком обращения, не имеет регулярных механизмов конвертации с финансовым капиталом, зато обеспечивает своему владельцу статус субъекта истории. Категория прокреационного капитала вносит в экономику модус гуманитарности.

Государство и индивид живут в разных временных масштабах, иными словами, принадлежат разным слоям временного континуума. Транзакции между ними являются транс-темпоральными. Поэтому они не укладываются в «плоскую» логику бухгалтерского баланса (дебит равен кредиту). И дебит, и кредит распределены во времени на десятки лет; они реализуются разными поколениями субъектов деятельности. Проблема их «дисконтирования» (приведения к единому моменту времени) пока не имеет четкого решения. Сейчас мы сможем проследить лишь некоторые качественные закономерности.

\section{Библиография}

РЕУт 2008: Реут, Д.В. Код культурной идентичности как положение в социуме центра ответственности за исполнение прокреационной функции // Национальная идентичность России и демографический кризис. Материалы IIBсеросс. научн. конф. (Москва, 15 ноября 2007 г.). - Москва: Научный эксперт, 419-428.

РЕУт 2009: Реут, Д.В. Прокреационный капитал. [Электрон. ресурс]/ Российский экономический конгресс. Сборник докладов участников. - Москва: ИЭ PAH, 1 CD-ROM (имя файла 14ts.doc в директории Files). http://econorus.org/consp/files/14ts.doc.

РЕут 2019: О культурных единицах и совокупностях, создаваемых ими и самовоспроизводящихся. Мир психологии, 2019/4: 187-204.

GidDEns 1990: Giddens, A. The Consequences of Modernity. Cambridge: Polity.

DARWIN 1859: Darwin, C. On the origin of species by means of natural selection. London: Murray. LefEBVRE 1982: Lefebvre, V.A. Algebra of Conscience. Dordrecht: Reidel, 222 p.

ORLOV 2013: Orlov, A. I. Functionalist-Organic Information Economy - the OrganizationalEconomic Theory of Innovation Development // Biocosmology - Neo-Aristotelism. Bilingual Electronic Journal of Universalizing Scientific and Philosophical Research based upon the Original Aristotelian Cosmological Organicism. Vol.3. №1 (Winter 2013). 
pp 52-59. URL: http://www.biocosmology.ru/elektronnyj-zurnal-biokosmologia-biocosmology-neo-aristotelism/postupivsie-stati/volume-3-number-1-winter-2013 (дата обращения 01.11.2010).

ORLOV 2018: Orlov, A. I. Nonparametric Method of Least Squares: Accounting for Seasonality // Journal of Mathematical Sciences. Vol. 228. № 5. February, 2018: 501-509.

SPENGLER 1927: Spengler, O. The Decline of the West. A. Knopf, New York.

SZUCS 2018a: Szucs O. Theory and practice from the point of view of risks in the culture of hygiene // Yudina, T.N., Tanatova, D.K. (ed.) Hygiene of culture: today's everyday practices and risks. Moscow: Association "For Hungarian-Russian cooperation name of Leo Tolstoy". Russian State Social University (Russia). Debrecen University (Hungary) 350-359.

SzUCS 2018b: Szucs O. The hygiene of culture in the context of system research // Szucs O. (ed.) The hygiene of culture. The questions of the future. Budapest: Association named after L.N. Tolstoy. 2018: 32-38.

TSVIRKUN-VARNAVSKY 2017: Tsvirkun, A., Varnavsky, V. Public-private partnerships in large-scale infrastructure in Russia: Opportunities and challenges // Proceedings of the 10th International Conference "Management of Large-Scale System Development" (MLSD). Moscow: IEEE. C. http://ieeexplore.ieee.org/document/8109702/ (дата обращения 01.11.2019)

TsVIRKUN-VASILIEV 2017: Tsvirkun, A., Vasiliev, S. Problems of managing the development of large-scale systems in modern conditions / Proceedings of the 10th International Conference "Management of Large-Scale System Development" (MLSD). Moscow: IEEE. C. http://ieeexplore.ieee.org/document/8109703/ (дата обращения 01.11.2019)

Дмитрий РЕУТ

Московский государственный технический университет им. Н.Э. Баумана Московский педагогический государственный университет Национальный исследовательский ядерный университет (МИФИ) dmreut@gmail.com; reut@bmstu.ru 